\title{
Guidelines for the management of haemophilia in Egypt
}

Galila Mokhtar, Amal El-Beshlawy, Mohssen El Alfy, Magdy El Ekiaby, Naglaa Omar, Khaled Abd El-Azim Eid, Hoda Hassab, Osama El Safy, Ahmed Mansour, Rasha El Ashry, Naglaa Shaheen, Prof. Dr Azza Abdel Gawad

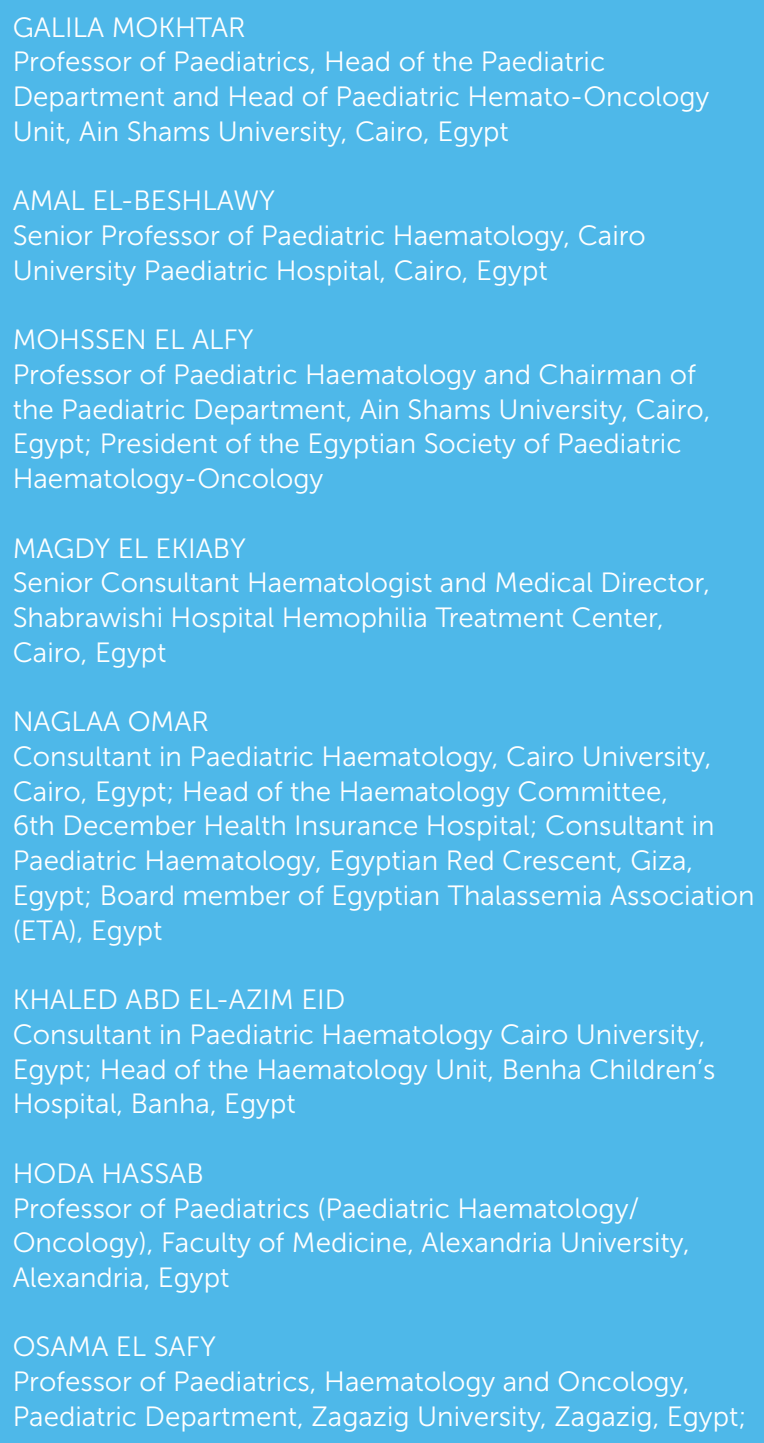

Head of the Paediatric Haematology and Oncology Unit, Zagazig Health Insurance Hospital, Zagazig, Egypt; Director of Zagazig University Thalassemia Association (ZUTA)

\section{AHMED MANSOUR}

Professor of Paediatrics (Haematology and Oncology) and Head of the Haematology and Oncology Unit, Faculty of Medicine, Mansoura University, Mansoura, Egypt

\section{RASHA EL ASHRY}

Professor of Paediatrics (Haematology, Oncology and Bone Marrow Transplantation), Mansoura Children's Hospital and Mansoura Oncology Centre, Mansoura, Egypt

\section{NAGLAA SHAHEEN}

Consultant in Paediatrics and Genetic Blood Disorders and official spokesperson of the National Health Insurance Organization, Egypt

PROF. DR AZZA ABDEL GAWAD

Professor of Paediatrics, Ain Shams University, Cairo, Egypt

These guidelines have been developed by an expert panel of haemophilia treaters to support the appropriate management of people with haemophilia in Egypt. Although the guidelines are based primarily on the World Federation of Hemophilia (WFH) Guidelines for the Management of Hemophilia, they aim to address unmet needs and local requirements in the Egyptian setting.

Keywords: Bleeding disorders, Egypt, Guidelines, Haemophilia, Management, Treatment 
T he healthcare system in Egypt is quite complex, with a large number of public entities involved in management, financing and the provision of care ${ }^{[1]}$. The World Federation of Hemophilia (WFH) Guidelines for the Management of Hemophilia are widely recognised as a gold standard to guide and inform the comprehensive management of haemophilia ${ }^{[2]}$. The guidelines proposed here have been developed to address important issues related to the comprehensive management of haemophilia in Egypt, including the management of circumcision and the hepatitis $C$ virus ( $\mathrm{HCV}$ ). It is important to note that these guidelines should be used as a supplement to WFH recommendations.

\section{GENERAL CARE AND MANAGEMENT OF HAEMOPHILIA}

\subsection{What is haemophilia?}

Haemophilia is an X-linked congenital bleeding disorder, caused by deficiency of coagulation factor VIII (haemophilia A) or factor IX (haemophilia B). According to the WFH, haemophilia has an estimated frequency of approximately one in 10,000 births.

Haemophilia A is more common than haemophilia $\mathrm{B}$, representing $80-85 \%$ of the total haemophilia population. According to the WFH Global Survey, there were an estimated 5,050 people with haemophilia (PWH)in Egypt in 2013 ${ }^{[2]}$.

The characteristic phenotype in haemophilia is the bleeding tendency, its severity generally correlating to the level of clotting factor level (Table 1). Haemophilia should be suspected in patients presenting with excessive bleeding following minor surgery, such as circumcision. Definitive diagnosis should be confirmed through factor assay to demonstrate deficiency of FVIII / FIX.

While bleeding tendency is life-long, people with haemophilia may not present with bleeding symptoms until later in life; for example, when they begin walking or running. Management of haemophilia is multifactorial and includes the prevention and treatment of bleeding, prevention of long-term joint damage, physical therapy, dental care, vaccinations, nutritional support, genetic counselling and psychological support.

\subsection{Principles of care}

The primary aim of care is to prevent and treat bleeding with the deficient clotting factor. Whenever possible, factor deficiency should be treated with factor concentrate (see section 4.2: Product selection). For optimal care, PWH should be treated within a comprehensive care setting. A patient's core management team should include a haematologist, nurse coordinator, laboratory specialist, musculoskeletal specialist, physical therapist, orthopaedic surgeon, hepatologist and psychological expert. The patient should also have access to a chronic pain specialist, dentist, geneticist, hepatologist, infectious disease specialist, immunologist, gynaecologist / obstetrician and vocational counsellor if possible.

In Egypt, children with haemophilia have, historically, received minimal dental intervention, and their needs require thorough assessment. Oral health education, plaque control, and access to oral care is paramount to improve the oral health of these children ${ }^{[3]}$.

\subsection{Nutrition and vaccination}

It is important for PWH to maintain good nutrition, particularly with respect to the absorption of key nutrients such as calcium, iron, and vitamins C and D. Management of patients who are overweight or obese is challenging and costly, requiring a constant follow-up on their nutrition, lifestyle, weight and physical activity levels. Adequate weight management should be encouraged. Immunisation against the hepatitis A and hepatitis $B$ viruses is mandatory for all $\mathrm{PWH}$, including routine hepatitis A vaccination in all patients over one year

Table 1: Relationship of bleeding severity to clotting factor level ${ }^{[1]}$

\begin{tabular}{l|l|l}
\hline SEVERITY & CLOTTING FACTOR LEVEL & BLEEDING EPISODES \\
\hline Severe & $\begin{array}{l}<1 \mathrm{IU} / \mathrm{dl}(<0.01 \mathrm{IU} / \mathrm{ml}) \text { or }<1 \% \\
\text { of normal }\end{array}$ & $\begin{array}{l}\text { Spontaneous bleeding into joints or muscles, predominantly in } \\
\text { the absence of identifiable haemostatic challenge }\end{array}$ \\
\hline Moderate & $\begin{array}{l}1-5 \mathrm{IU} / \mathrm{dl}(0.01-0.05 \mathrm{IU} / \mathrm{ml}) \\
\text { or } 1-5 \% \text { of normal }\end{array}$ & $\begin{array}{l}\text { Occasional spontaneous bleeding; prolonged bleeding with } \\
\text { minor trauma or surgery }\end{array}$ \\
\hline Mild & $\begin{array}{l}5-40 \mathrm{IU} / \mathrm{dl}(0.05-0.40 \mathrm{IU} / \mathrm{ml}) \\
\text { or } 5-<40 \% \text { of normal }\end{array}$ & $\begin{array}{l}\text { Severe bleeding with major trauma or surgery. Spontaneous } \\
\text { bleeding is rare }\end{array}$ \\
\hline
\end{tabular}


of age ${ }^{[1]}$. Patients over five years of age should be screened for hepatitis $B$ virus and revaccinated if negative. Vaccination should be subcutaneous, rather than intramuscular or intradermal.

\section{RECOMMENDATIONS}

- Healthcare for all PWH should include nutritional advice and follow-up - calcium, iron (guided by iron (evel) and vitamins $C$ and $D$

- Routine hepatitis A vaccination in all haemophilic patients $>1$ year of age is mandatory

- Hepatitis B screening is essential for PWH $>5$ years of age, and it is important to revaccinate those who are negative

\subsection{Home treatment}

Early treatment of bleeds minimises the amount of blood in affected joints, resulting in improved short- and long-term outcomes, such as reduced pain and swelling, as well as reduced joint damage. Home treatment allows a patient immediate access to clotting factor, meaning optimal early treatment is possible, helping to stop bleeding and reduce longterm damage.

In addition to increasing factor levels with clotting factor concentrates (or desmopressin in mild haemophilia A), muscle and joint bleeds can also be managed through first aid measures such as PRICE: Protection (use of splints), Rest, Ice (applied to the site of the bleed), Compression, Elevation. In the case of mucosal bleeds or dental extractions, antifibrinolytic drugs (eg tranexamic acid, epsilon aminocaproic acid) can be an effective adjunct treatment. Home treatment is also necessary for the effective use of prophylaxis.

Where home treatment programs are available, there is a reduction in clinic visits and hospital admissions, easing the burden on public health facilities. Nevertheless, it is important to ensure a regular clinic visit (every three months) for follow-up. Training and education is also very important for both parents and patients, particularly:

- How to self-infuse

- How to keep bleeding records

- How to transport, store and use factor

- How to dispose of needles

- How to handle blood spills

- How to manage complications when treating
RECOMMENDATIONS

- Home treatment should be encouraged; however, it is important that regular clinic visits continue to ensure good management of haemophilia

- First aid measures and antifibrinoloytic agents are encouraged as adjuvant therapy

- Parents and patients should be educated on all the steps underlying home treatment to build confidence, ensure safety and promote it as an option for the management of haemophilia

\subsection{Physiotherapy}

Physiotherapy is important in the management of haemophilia to prevent and treat musculoskeletal damage ${ }^{[4]}$. In addition to clotting factor concentrates, usually prescribed by the haematologist, management of acute haemarthrosis and chronic arthropathy requires close collaboration between the orthopaedic surgeon and physiotherapist. Collaboration between coagulation and musculoskeletal specialists is key to effectively preventing haemarthrosis, managing acute joint bleeding episodes, assessing joint function and actively treating chronic arthropathy ${ }^{[5]}$. Physiotherapy should be initiated as soon as the pain subsides and should be continued to gradually restore full muscle length, strength and function.

Evaluation of joint status, its progress and the impact on quality of life represent an integral part of the consultation. A short and easy scoring system can be used to support the evaluation of joint health and should be adopted to monitor patient outcomes ${ }^{[5]}$.

\section{RECOMMENDATIONS}

- The haemophilia treater should talk directly with the local physiotherapist to provide education on the special needs of treating $\mathrm{PWH}$, specifically regarding the use of factor replacement therapy, prior to the physiotherapy session

- Physiotherapy manoeuvres are best carried out immediately after factor infusion

- A short and easy scoring system, such as the Hemophilia Joint Health Score (HJHS), should be adopted to evaluate joint health

\section{SPECIAL MANAGEMENT ISSUES}

\subsection{Hepatitis C virus in Egypt}

Egypt has the highest prevalence of hepatitis $C$ virus (HCV) in the world, with $14.7 \%$ of people aged $15-59$ 
years old affected ${ }^{[6]}$. The high prevalence is thought to have resulted from transmission during parenteral antischistosomal therapy (PAT) mass treatment ${ }^{[7]}$. Current risk of transmission, both through healthcare and in the community, is still considered to be substantial.

Knowledge about the viral load distribution in different stages of HCV infection is essential to compare the efficacy of serologic screening and nucleic acid testing in preventing transfusion transmission risk. Studies have been conducted on the HCV-RNA levels in Egyptian blood donors in the pre-seroconversion window period and in later anti-HCV-positive stages of infection ${ }^{[8]}$

Prevention of HCV transmission in $\mathrm{PWH}$ is a priority of care in Egypt and regular screening is important, even in asymptomatic patients. Patients should be educated on the potential risks underlying the use of blood products and stricter policies are needed to protect them. For HCV-positive patients with haemophilia, treatment should also be provided.

\section{RECOMMENDATIONS}

- PWH should be regularly screened for HCV, even if they are asymptomatic

- Patients should be educated on the potential risks underlying the use of blood products

- Stricter policies on blood products are required

- HCV-positive patients with haemophilia should be provided with appropriate treatment

\subsection{Psychosocial issues}

Psychosocial factors have a significant impact on the quality of life of patients with chronic diseases such as haemophilia. Interventions to support the psychosocial needs of patients and their carers - for example, providing information and assistance, clarifying doubts, and teaching coping strategies to minimise the impact of disabilities - may help to maximise patient outcomes and improve the quality of life of both themselves and their families ${ }^{[9,10]}$.

Various programs and studies have shown that offering psychological support to parents following the diagnosis of haemophilia has positive results. Parents who participated in a program of monthly psychological support and counselling, for example, showed significant progression, in pre- and post-study tests, in the greater use of problem-focused coping strategies (recognition that a situation can change), and a reduced use of emotion-focused strategies (indicative of no change) ${ }^{[11]}$.

\section{RECOMMENDATIONS}

- PWH and their families should be provided with access to psychological and social support, with a focus on patient and family education, and addressing the emotional burden of the disease on the patient

- Increased awareness of haemophilia is also needed among healthcare providers and the general population, for example through medical caravans and the media

\subsection{Circumcision}

In Egypt, circumcision is an important cultural practice and must be considered in patients with haemophilia. Modern haemophilia treatment aims to integrate $\mathrm{PWH}$ in society, acknowledging and respecting their culture and beliefs. Such an approach is vital in order to succeed in haemophilia management in Egypt ${ }^{[12]}$.

Despite the high costs of the procedure and the risks of developing inhibitors, social demand for the circumcision of boys with haemophilia is significant ${ }^{[12]}$.

Since the risks of developing inhibitors is higher during the neonatal period, postponing circumcision until after six months of age is advisable, and between six and 18 months is preferred ${ }^{[12,13]}$.

\section{RECOMMENDATIONS}

- Circumcision of PWH and/or those with a positive family history of haemophilia should not be considered a minor surgical procedure and must be performed under strict conditions

- Administration of clotting factor concentrate (even if minimal) is usually required before circumcision and should be continued during the week following the procedure

\subsection{Surgical procedures}

Surgical and invasive procedures can be performed safely in PWH with appropriate management.

\section{Classification of surgery}

Surgery is classified as 'major' and 'minor' according to perceived or proven bleeding risk. Major surgery often refers to major abdominal, intracranial, cardiovascular, spinal, major orthopaedic and any other surgery which has a significant risk of large volume blood loss or blood loss into a confined anatomical space. In children this may include adeno-tonsillectomy. 
Table 2: Clotting factor concentrate replacement before and after surgery

\begin{tabular}{|c|c|c|c|c|c|c|}
\hline $\begin{array}{l}\text { TYPE OF } \\
\text { SURGERY }\end{array}$ & $\begin{array}{l}\text { HAEMOPHILIA } \\
\text { DESIRED } \\
\text { LEVEL (IU/ML) }\end{array}$ & $\begin{array}{l}\text { DURATION } \\
\text { (DAYS) }\end{array}$ & $\begin{array}{l}\text { INTERVAL } \\
\text { FREQUENCY } \\
\text { (HOURS) }\end{array}$ & $\begin{array}{l}\text { HAEMOPHILIA } \\
\text { DESIRED } \\
\text { LEVEL (IU/ML) }\end{array}$ & $\begin{array}{l}\text { DURATION } \\
\text { (DAYS) }\end{array}$ & $\begin{array}{l}\text { INTERVAL } \\
\text { FREQUENCY } \\
\text { (HOURS) }\end{array}$ \\
\hline \multicolumn{7}{|c|}{ Major surgery } \\
\hline Pre-op & $80-100$ & & & $60-80$ & & \\
\hline \multirow[t]{3}{*}{ Post-op } & $60-80$ & $1-3$ & $8-12$ & $40-60$ & $1-3$ & 12 \\
\hline & $40-60$ & $4-6$ & $8-12$ & $30-50$ & $4-6$ & 12 \\
\hline & $30-50$ & $7-14$ & 12 & $20-40$ & $7-14$ & 24 \\
\hline \multicolumn{7}{|c|}{ Minor surgery } \\
\hline Pre-op & $>50$ & & & $>50$ & & \\
\hline Post-op & & $\begin{array}{l}\text { 1-5 depending } \\
\text { on type of } \\
\text { procedure }\end{array}$ & 12 & & $\begin{array}{l}\text { 1-5 depending } \\
\text { on type of } \\
\text { procedure }\end{array}$ & 24 \\
\hline \multicolumn{7}{|c|}{$\begin{array}{l}\text { FVIII/FIX should be monitored peri-operatively-, immediately postoperative and at least once daily in the } \\
\text { hospitalised period }\end{array}$} \\
\hline
\end{tabular}

Minor surgery refers to removal of skin lesions, arthroscopy, minor dental procedures and dental extractions, etc.

\section{Elective surgery}

For PWH, elective surgery should be planned ideally for late morning or early afternoon. The patient's haemostatic function should be screened prior to surgery. Laboratory tests for platelet count, activated partial thromboplastin time (APTT), prothrombin time, FVIII/FIX level, inhibitor test, fibrinogen, blood group and a recovery test should be performed prior to surgery.

\section{Factor concentrate replacement}

Table 2 (above) shows the recommended treatment with factor concentrate before and after major and minor surgery.

\section{Analgesia}

Non-steroidal anti-inflammatory drugs (NSAIDs) are generally contraindicated but COX-2 inhibitors can be used.

\section{Anti-fibrinolytic therapy}

Tranexamic acid (25 mg/kg p.o / 10 mg/kg i.v.) should be combined with factor replacement 3-4 times daily for 7-10 days.

\section{RECOMMENDATIONS}

- Due to the increased risk of bleeding during surgery, the surgical team should work with the local haemophilia treatment centre to thoroughly plan procedures prior to surgery

- Prior to surgery, the haematologist should provide a written detailed treatment plan including duration and dosage of haemostatic therapies, also covering the rehabilitation phase

\section{LABORATORY DIAGNOSIS}

\subsection{Principles of diagnosis}

Early diagnosis is important for the effective management of haemophilia. A correct diagnosis is essential to ensure that the patient receives the appropriate treatment, particularly considering that different bleeding disorders may have very similar symptoms ${ }^{[1]}$.

Accurate diagnosis can only be made with the support of a comprehensive and accurate laboratory service. Screening tests should be used to identify the potential cause of bleeding; for example, platelet count, bleeding time (in select situations) or other platelet function screening tests, prothrombin time (in select situations), and activated partial thromboplastin time (APTT) ${ }^{[4]}$. Diagnosis should be confirmed by factor assays and other appropriate specific investigations. A central laboratory to confirm factor level is mandatory. Genotyping is essential; however, services are currently lacking in Egypt. 
RECOMMENDATIONS

- Specific WFH guidelines on laboratory practices for the diagnosis of haemophilia should be followed

\subsection{Detection of inhibitors}

The development of inhibitors in PWH is one of the most serious complications of haemophilia management today ${ }^{[1]}$.

Inhibitors in haemophilia refer to immunoglobulin G (IgG) antibodies that neutralise or limit the effectiveness of clotting factor concentrates ${ }^{[4]}$. Depending on the potency of inhibitors present, treatment may be rendered partly or completely ineffective, resulting in increased morbidity ${ }^{[14,15]}$. Inhibitor development is multifactorial, with genetic and non-genetic risk factors involved. Inhibitors occur in about $30 \%$ of previously untreated patients (PUPs) with severe haemophilia A, usually within the first 50 to 100 exposure days (EDs) but a baseline low risk remains throughout a patient's life ${ }^{[16,17]}$. The impact of treatment-related factors on inhibitor development in PUPs with haemophilia $A$ is still under debate ${ }^{[18]}$

\section{RECOMMENDATIONS}

- Specific WFH guidelines on the detection of inhibitors should be followed

\section{HAEMOSTATIC AGENTS AND DOSING REGIMENS}

\subsection{Clotting factor concentrates}

There are two categories of FVIII and FIX concentrate for the treatment of haemophilia A and B: respectively, plasma-derived and recombinant. Plasma-derived clotting factor is manufactured from large pools of human plasma, and undergoes various processes that aim to inactivate and eliminate known blood-borne viruses. Recombinant clotting factor concentrates are manufactured from genetically engineered cell lines and undergo multiple purification steps, specific to product manufacturers.

\subsection{Product selection}

Currently available therapeutic options for the management of haemophilia are highly effective. When selecting a coagulation factor, the main considerations are product safety and cost.

On a global scale, between 1970 and 1980, large numbers of people with haemophilia became infected with blood-borne viruses due to contaminated plasma-derived FVIII and FIX ${ }^{[19]}$. Careful selection of blood donors, screening of plasma, and advances in the manufacturing of clotting factor concentrates have led to an almost complete elimination of the risk of known viral transmissions. However, despite advances in preventing the transmission of known lipid-enveloped blood-borne viruses, blood can never be considered completely sterile as there are transitory or permanently circulating viruses that are not currently screened for. These include hepatitis E virus, Epstein-Barr virus, parvoviruses, cytomegaloviruses and Torque teno virus (TTV) ${ }^{[20]}$. Additionally, nonlipid-enveloped pathogens may survive current viral inactivation processes, and emerging viral and non-viral pathogens, such as prions, should also be considered ${ }^{[21]}$

The risk of prion-mediated disease through plasma-derived products is higher in the absence of a reliable screening test for variant Creutzfeldt-Jakob disease (VCJD), and where there are no established manufacturing steps to inactivate the VCJD prion.

It is also important to identify the persistence of inhibitors against factor VIII, for example, as this may be a risk factor that increases physical disability in haemophilia A patients ${ }^{[22]}$. However, the development of neutralising anti-FVIII inhibitors are not only dependent on the concentrate used ${ }^{[23]}$.

\section{RECOMMENDATIONS}

- Recombinant clotting factor concentrates are the recommended treatment of choice for $\mathrm{PWH}$ in Egypt. If resources are limited, virally inactivated plasma-derived concentrates can be used

- Due to the high prevalence of HCV in Egypt, cryoprecipitate, fresh frozen plasma, and solventdetergent filtered cryoprecipitate should only be used in emergency situations where no alternatives are available

\subsection{Prophylaxis vs. on-demand treatment}

Prophylaxis is the use of factor concentrate to prevent anticipated bleeding (Table 3$)^{[4]}$.

Prophylactic treatment has been shown to result in fewer haemarthroses, less arthropathy, fewer muscle bleeds, less frequent monitoring, fewer hospital admissions, reduced risk of cerebral bleeding, less joint surgeries, less time off work, lower disability and improved quality of life for $\mathrm{PWH}^{[24]}$.

It has been shown that patients on prophylactic and on-demand treatment regimens may use similar 
Table 3: Definitions of factor replacement therapy protocols ${ }^{[1]}$

\begin{tabular}{|c|c|}
\hline PROTOCOL & DEFINITION \\
\hline $\begin{array}{l}\text { On-demand } \\
\text { treatment (episodic) }\end{array}$ & Treatment given at the time of clinically evident bleeding \\
\hline Primary prophylaxis & $\begin{array}{l}\text { Regular continuous* treatment initiated in the absence of documented osteochondral joint } \\
\text { disease, determined by physical examination and / or imaging studies, and started before the } \\
\text { second clinically evident large joint bleed and age three years** }\end{array}$ \\
\hline $\begin{array}{l}\text { Secondary } \\
\text { prophylaxis }\end{array}$ & $\begin{array}{l}\text { Regular continuous* treatment started after two or more bleeds into large joints** and before } \\
\text { the onset of joint disease documented by physical examination and imaging studies }\end{array}$ \\
\hline Tertiary prophylaxis & $\begin{array}{l}\text { Regular continuous* treatment started after the onset of joint disease documented by physical } \\
\text { examination and plain radiographs of the affected joints }\end{array}$ \\
\hline $\begin{array}{l}\text { Intermittent } \\
\text { prophylaxis (periodic) }\end{array}$ & Treatment given to prevent bleeding for periods not exceeding 45 weeks in a year \\
\hline
\end{tabular}

* Continuous is defined as the intent of treating for 52 weeks per year and receiving a minimum of an a priori defined frequency of infusions for at least 45 weeks (85\%) of the year under consideration

** Large joints: ankles, knees, hips, elbows and shoulders

amounts of factor annually. Therefore, compared with a primarily on-demand treatment strategy, a primarily prophylactic treatment strategy can lead to better outcomes at equivalent treatment cost ${ }^{[23,25-26]}$.

\subsection{Cryoprecipitate}

In Egypt, due to cost and resource constraints, both virally inactivated cryoprecipitate by solvent and detergent (S/D) and virally inactivated plasma by S/D are used for the management of patients with haemophilia.

Data have shown that S/D filtration cryoprecipitate FVIII "can be safely used for the control of acute and chronic bleeding episodes in haemophilia A patients" [27] but should only be used in "situations where clotting factor concentrates are not available" [2].

Regarding dosage, the WFH highlights that "a bag of cryoprecipitate made from one unit of fresh frozen plasma (200-250ml) may contain 70-80 units of FVIII in a volume of $30-40 \mathrm{ml}^{\text {[2]. }}$.

\subsection{Fresh frozen plasma}

Fresh frozen plasma (FFP) is a limited option for treating coagulation factor deficiencies as it is generally difficult to achieve FVIII levels higher than $30 \mathrm{IU} / \mathrm{dl} .2$

Although FFP can be used for the treatment of haemophilia $B$ in countries with limited resources to afford plasma-derived FIX concentrates, the WFH does not recommend its use due to safety and quality concerns ${ }^{[2]}$.

RECOMMENDATIONS
for all PWH to preserve musculoskeletal function,
as it helps to prevent bleeding and joint damage.
It is cost-effective in the long term as it eliminates
costs associated with the management of
damaged joints and improves quality of life
Low-dose (recombinant third generation 40 IU/
kg) [28] prophylaxis two to three times per week is
an effective option, but should be individualised
according to age, venous access, bleeding
phenotype, activity and availability of clotting
factor concentrates
For the treatment of very young children, one
option is to start prophylaxis once per week and
escalate the frequency depending on bleeding
and venous access

\section{COMPLICATIONS OF HAEMOPHILIA}

\subsection{Synovectomy}

Approximately $80-90 \%$ of bleeding episodes in haemophilia occur in the musculoskeletal system, especially in the large synovial joints (elbows, knees, ankles, hips and shoulders) ${ }^{[4]}$. Chronic haemophilic synovitis is characterised by persistent joint swelling and proliferative synovitis ${ }^{[29]}$.

A reduction of the hypertrophied synovium is the key to preventing recurrent intra-articular haemorrhages ${ }^{[29]}$. The vicious cycle of haemarthrosissynovitis-haemarthrosis secondary to recurrent 


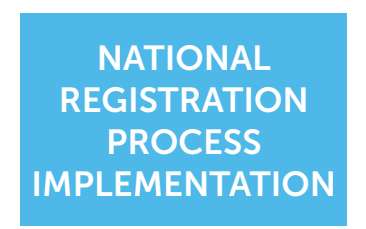

Population with
haemophilia in Egypt: $5,200+$

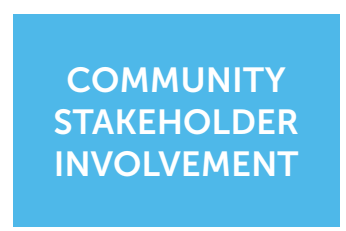

Public health insurance Ministry of Health University Hospitals

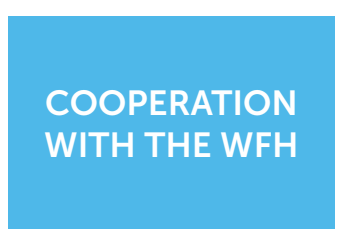

Twinning programme GAP program

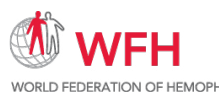

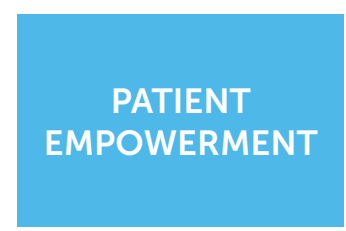

Awareness and educational activities

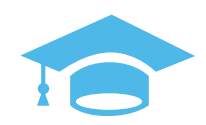

WORLD HAEMOPHILIA DAY

Annual celebration of haemophilia

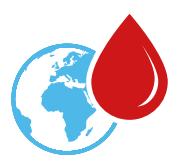

haemarthroses must be interrupted as soon as possible to avoid the development of haemophilic arthropathy ${ }^{[29]}$.

Synovectomy should be considered if chronic synovitis persists with frequent recurrent bleeding and cannot be controlled by other means ${ }^{[1]}$. If a radioisotope is not available, chemical synovectomy with rifampicin is an appropriate alternative ${ }^{[1]}$; however, chemical synovectomy can be more painful than radioactive synovectomy ${ }^{[30]}$. A combined prospective study comparing chemical (rifampicin) vs. radioactive (90Y) synovectomy showed similar results with both methods ${ }^{[30]}$.

\section{RECOMMENDATIONS}

- Non-surgical synovectomy, guided by ultrasound, is the procedure of choice

- Chemical synovectomy should be used when appropriate and available. Rifampicin is highly effective and has few side effects; it can be used in an outpatient setting when preceded and followed by factor infusion, analgesics and bed rest.

\section{THE EGYPTIAN SOCIETY OF HEMOPHILIA AND ITS STRATEGIC OBJECTIVES}

\subsection{Introduction to the Egyptian Society of Hemophilia (ESH)}

The regular management of haemophilia in Egypt started through the establishment of a Diagnostic Unit of Inherited Bleeding Disorders (IBD) in the Central Health Laboratories of the Ministry of Health $(\mathrm{MoH})$ and a haemophilia treatment centre in the National Institute of Diabetes, in 1968. Three years later, Dr Bothaina El Shenawy, together with a group of interested haematologists and haemophilia patients, founded the Egyptian Society of Hemophilia (ESH).

The role of the ESH is aligned with the aims of the World Federation of Hemophilia (WFH). Cooperating with the WFH, the ESH is focused on improving care for and empowering people with IBDs.

The objectives of the ESH are to:

1. Accurately identify IBD through $\mathrm{MoH}$ laboratories and blood research departments

2. Establish and maintain a national registry to accurately determine the epidemiological data of IBD and improve decision-making on adequate treatments

3. Increase public awareness about IBD and advocate for patients with haemophilia rights in accessing appropriate healthcare and integration in the society through:

- Free education

- Exemption from military service

- Employment rights similar to other impairment disorders

4. Scientific research in the field of IBD

5. Cooperation with other national and international organisations that can help to improve care of patients with IBD.

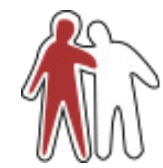

\section{Egyptian Society of Hemophilia} جمعية أصدقاء مرضى النزف

\subsection{National care program for IBD}

As a result of the work by the ESH there are now over 20 haemophilia treatment centres across the country, IBDs have become a government priority, and the budget allocated to care and treatment for IBDs is progressively increasing. 


\subsection{ESH vision and strategic plan (2018)}

The ESH is committed to supporting the continued development and expansion of Egypt's national care program for IBDs, and improving the lives of $\mathrm{PWH}$ in Egypt through the six-point strategic plan outlined below.

\section{PUBLIC AWARENESS}

Increase knowledge of inherited bleeding disorders (IBDs) among healthcare professionals and in the community, particularly through governmentsupported initiatives

\section{PRODUCT AVAILABILITY}

Increase the availability of FVIII from $0.36 \mathrm{IU} /$ capita to $0.86 \mathrm{IU} /$ capita

\section{NATIONAL GUIDELINES}

Establish national management guidelines for haemophilia and other IBDs, and ensure regular reviews and updates

\section{DIAGNOSIS}

Introduce a national screening program for inhibitors to FVIII and FIX

\section{NATIONAL REGISTRATION}

Introduce regular evaluation of management outcomes and establish a national registry for haemophilia and other IBDs

\section{COMMUNITY SUPPORT}

Increase government support for the rehabilitation of patients with IBDs

\section{ACKNOWLEDGEMENTS}

Funding for the development of the guidelines was provided by Pfizer through an Advisory Board. Pfizer did not influence the content development of the guidelines.

Editorial support to prepare the guidelines was provided by the medical writing team at SYNERGY (London, UK), a Medical Education agency. This support was funded by Pfizer.

The Egyptian Expert Panel would like to thank Dr Gerry Dolan (Haemophilia Centre Director, St Thomas' Hospital, London, UK) for his advice and guidance during the development of these guidelines.
This article does not contain any studies involving human participants or animals performed by any of the authors.

\section{REFERENCES}

1. World Health Organization. Country Cooperation Strategy for WHO and Egypt 2010-2014. Cairo, Egypt: World Health Organization Regional Office for the Eastern Mediterranean, 2010. Available from http://who.int/countryfocus/cooperation strategy/ ccs_egy_en.pdf?ua=1 (accessed October 2016).

2. World Federation of Hemophilia. Guidelines for the management of hemophilia. 2nd edition. 2012. Available from https://www1.wfh.org/publications/files/pdf-1472.pdf (accessed 24 September 2018).

3. Kabil N, ElAlfy MS, Metwalli N. Evaluation of the oral health situation of a group of Egyptian haemophilic children and their re-evaluation following an oral hygiene and diet education programme. Haemophilia 2007;13:287-92.

4. Srivastava A, Brewer AK, Mauser-Bunschoten EP, et al; Treatment Guidelines Working Group on Behalf of the World Federation of Hemophilia. Guidelines for the management of hemophilia. Haemophilia 2013; 19: e1-e47.

5. Lobet $\mathrm{S}$, Hermans $\mathrm{C}$, Lambert C. Optimal management of hemophilic arthropathy and hematomas. J Blood Med 2014: 5; 207-18.

6. El-Zanaty F, Way A. Egypt Demographic and Health Survey 2008. Cairo, Egypt: Ministry of Health, El-Zanaty and Associates, and Macro International, 2009. Available from https://dhsprogram.com/pubs/pdf/fr220/fr220.pdf (accessed 24 September 2018).

7. Mohamoud YA, Mumtaz GR, Riome S, Miller D, Abu-Raddad LJ. The epidemiology of hepatitis $C$ virus in Egypt: a systematic review and data synthesis. BMC Infect Dis 2013; 13: 288.

8. El Ekiaby M, Moftah F, Goubran H, et al. Viremia levels in hepatitis $C$ infection among Egyptian blood donors and implications for transmission risk with different screening scenarios. Transfusion 2015; 55: 1186-94.

9. Cassis FR, Querol F, Forsyth A, lorio A, HERO International Advisory Board. Psychosocial aspects of haemophilia: a systematic review of methodologies and findings. Haemophilia 2012; 18: e101-14.

10. Tantawy A, von Mackenssen S, Mohammed AM, et al. Health-related quality of life in Egyptian children and adolescents with hemophilia A. Pediatr Hematol Oncol 2011; 28: 222-9.

11. Bottos AM, Zanon E, Sartori MT, Girolami A. Psychological aspects and coping styles of parents with haemophilic child undergoing a programme of counselling and psychological support. Haemophilia 2007; 13: 305-10.

12. Zulfikar B, Karaman MI, Ovali F. Circumcision in hemophilia: an overview. 2003. Available from www1.wfh.org/publication/ files/pdf-1170.pdf (accessed October 2016).

13. Elalfy MS, Elbarbary NS, Eldebeiky MS, El Danasoury AS. Risk of bleeding and inhibitor development after circumcision of previously untreated or minimally treated severe hemophilia A children. Pediatr Hematol Oncol 2012; 29: 485-93.

14. Paisley S, Wight J, Currie E, Knight C. The management of inhibitors in haemophilia A: introduction and systematic review of current practice. Haemophilia 2003; 9: 405-17. 
15. Rivard GE, Rothschild C, Toll T, Achilles K. Immune tolerance induction in haemophilia $A$ patients with inhibitors by treatment with recombinant factor VIII: a retrospective noninterventional study. Haemophilia 2013; 19: 449-55.

16. European Medicines Agency. Guideline on the clinical investigation of recombinant and human plasma-derived factor VIII products. EMA/CHMP/BPWP/144533/2009. Available from https://www.ema.europa.eu/documents/ scientific-guideline/guideline-clinical-investigationrecombinant-human-plasma-derived-factor-viii-productsfirst-version_en.pdf (accessed 4 October 2018)..

17. Iorio A, Puccetti P, Makris M. Clotting factor concentrate switching and inhibitor development in hemophilia A. Blood 2012; 120: 720-27.

18. Marcucci M, Mancuso ME, Santagostino E, et al. Type and intensity of FVIII exposure on inhibitor development in PUPs with haemophilia A. A patient-level meta-analysis. Thromb Haemost 2015; 113: 958-67.

19. Di Minno G, Canaro M, Ironside JW, et al. Pathogen safety of long-term treatments for bleeding disorders: still relevant to current practice. Haematologica 2013; 98: 1495-98.

20. Di Minno G, Canaro M, Ironside JW, et al. Pathogen safety of long-term treatments for bleeding disorders: (un)predictable risks and evolving threats. Semin Thromb Haemost 2013; 39: 779-93.

21. Key NS, Negrier C. Coagulation factor concentrates: past, present, and future. Lancet 2007; 370: 439-48.
22. Abdel-Messih IY, Habashy DM, Moftah SG, ElAlfy MS. Persistent factor VIII inhibitors and orthopaedic complications in children with severe haemophilia A. Haemophilia 2011; 17: 490-3.

23. Peyvandi F, Mannucci PM, Garagiola I, et al. A randomized trial of factor VIII and neutralizing antibodies in hemophilia A. N Engl J Med 2016; 374: 2054-64.

24. Makris M. Prophylaxis in haemophilia should be life-long Blood Transfus 2012; 10: 165-8.

25. Fischer K, van der Bom JG, Molho P, et al. Prophylactic versus on-demand treatment strategies for severe haemophilia: a comparison of costs and long-term outcome. Haemophilia 2002; 8: 745-52

26. Elekiaby A, El Saied H, Elekiaby M. Five years of tailored low dose prophylaxis in a small cohort of kids with severe hemophilia A using SD-F cryoprecipitate. Poster no. PO169 presented at the World Federation of Hemophilia Congress; 24-28 July 2016; Orlando, FL.

27. El-Kiaby M, Goubran HA, Radosevich M, et al. Pharmacokinetic study of minipooled solvent/detergent filtered cryoprecipitate factor VIII. Haemophilia 2011; 17: e884-8.

28. BeneFIX: Summary of product characteristics, 2016.

29. Rodriguez-Merchan EC. Methods to treat chronic haemophilic synovitis. Haemophilia 2001; 7: 1-5.

30. Rodriguez-Merchan EC, Caviglia HA, Magallon M, PerezBianco R. Chemical synovectomy vs. radioactive synovectomy for the treatment of chronic haemophilic synovitis: a prospective short- term study. Haemophilia 1997; 3: 118-22.

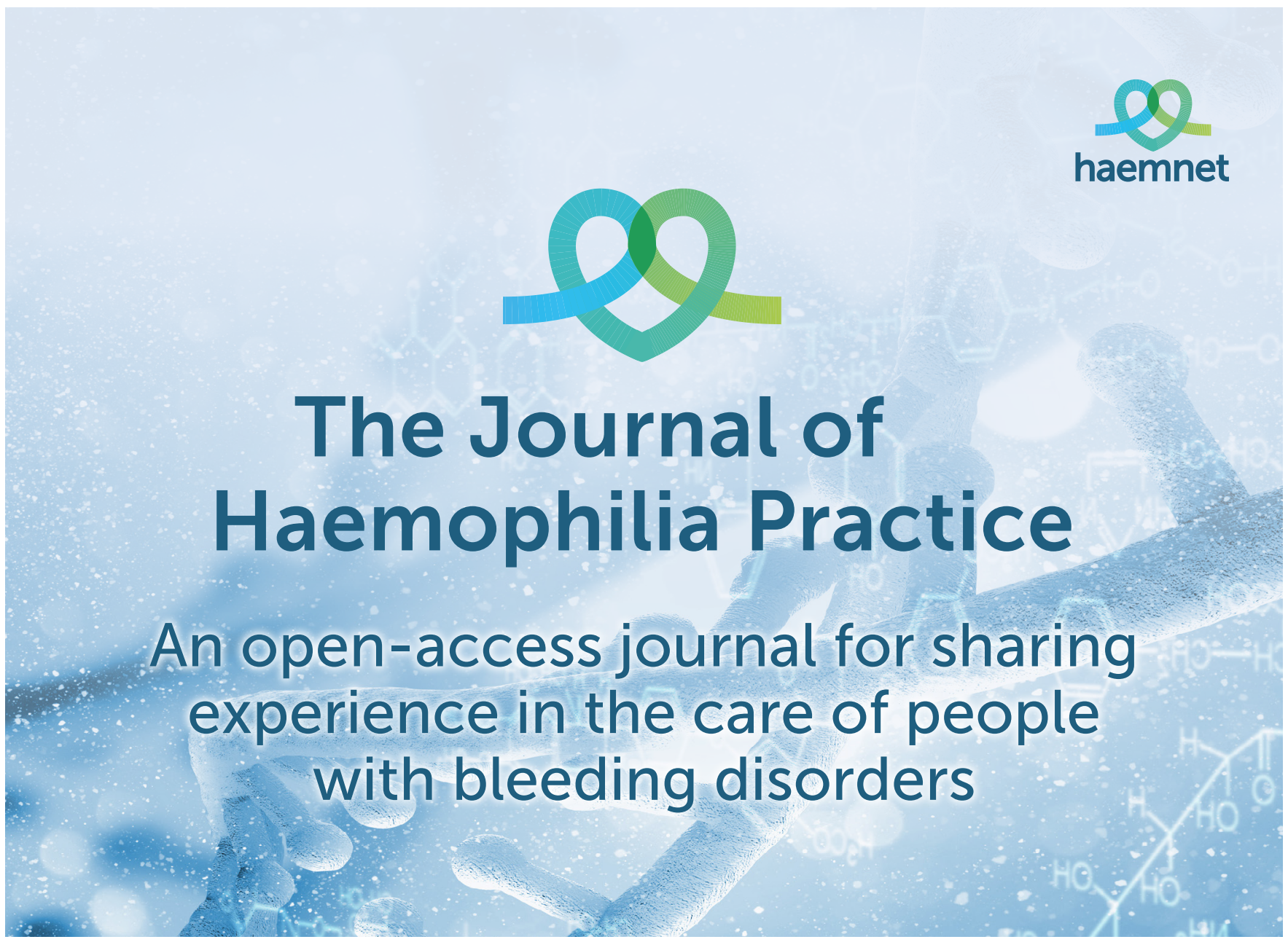

